\title{
Application of Simulation Negotiation Teaching Method in the Course of "Business Negotiation" for Cadets
}

\author{
Yuanli Zhao, Yunpeng Xiao, Xi Chen, Jiansong Li \\ Aviation Quartermaster and Fuel Department \\ Air Force Service College \\ Xuzhou, Jiangsu, China
}

\begin{abstract}
The application of the simulation negotiation method in business negotiation teaching can not only enable the cadets to easily grasp the corresponding theoretical knowledge, but also improves the comprehensive negotiation skills effectively. Based on the analysis of the necessity and significance of simulation teaching, this work focuses on the practical application of simulation negotiation, and put forward reasonable suggestions for improving the problems existing in simulation negotiation.
\end{abstract}

Keywords—simulation negotiation method; cadets; application of the course

\section{INTRODUCTION}

The course of Business Negotiation is very practical. If the trainees only have theoretical knowledge and lack of practical operation in the teaching process of military academies, it is obviously not in line with the teaching requirements of this course. In recent years, most $\mathrm{f}$ members have used case analysis teaching methods in practice teaching, but case analysis has certain limitations in the teaching of this course [1] Firstly, because of the confidentiality of the company or the unit, it is difficult for the instructors to find real cases to assist in teaching. Secondly, the case analysis usually only involves a certain part of the negotiation, which lack coherence, and it is difficult to make the knowledge acquired comprehensively [2]. The so-called simulation negotiation is the rehearsal before the formal negotiations. It is the last item in the preparation of business negotiations. It selects some people from its own side to play the role of the negotiating opponent, puts forward various assumptions and conjectures, and carries out the imaginary practice and actual performance of negotiation with the main negotiators of its own side based on the negotiating position, viewpoint and style of the opponent. If the module of the actual business negotiation process is simulated in the practice teaching link, it can not only effectively test the students' mastery of theoretical knowledge, but also stimulate students' learning interest by creating coherent and highly simulated business negotiation scenarios, so as to improve students' ability to solve problems with what they have learned [3].

\section{Problems in the ApPlication of the Simulation Negotiation METHOD IN THE COURSE OF BusinesS NEGOTIATION}

Simulation negotiation for the course of Business Negotiation, the necessity of its development is reflected in the following aspects:

\section{A. Improving the ability to cope with difficulties}

Mode negotiations can enable negotiators to gain practical experience and improve their ability to cope with various difficulties. Many successful negotiation examples and psychological research results have shown that the correct imagination exercise can not only improve the negotiator's independent analysis ability, but also is very beneficial in the aspects of psychological preparation, psychological bearing, on-the-spot display and so on. In the simulation negotiation, the negotiators can play themselves and even play opponents again and again, so that they are familiar with all aspects of the actual negotiation. This is especially important for those who are participating in the negotiations for the first time.

\section{B. Testing whether the negotiation plan is thorough and feasible}

The negotiation plan is formulated by the members of the negotiation group under the chairmanship of the person in charge of the negotiation group. It is an anticipation of the formal negotiations that will take place in the future, which by itself cannot fully reflect some of the unexpected things that have emerged in the formal negotiations. At the same time, negotiators are limited by factors such as knowledge, experience, way of thinking, position and angles to consider issues, so it is inevitable that there will be shortcomings and loopholes in the formulation of negotiation plans. In fact, whether the negotiation plan is perfect or not can only be truly tested in formal negotiations, but this is, after all, an after-thefact test, and it is often too late to find the problem. The simulation negotiation is a simulation of actual formal negotiations, which is closer to formal negotiations. Therefore, it can comprehensively and strictly test whether the negotiation plan is feasible, check the problems and deficiencies in the negotiation plan, and timely revise and adjust the negotiation plan. 


\section{Training and improving negotiation skills}

The opponents of the simulation negotiation are their own personnel, who are very familiar with their own situation. At this time, putting forward questions in the position of the opponents can help to find out the mistakes in the negotiation plan, and predict which aspects the opponent may put forward questions, so as to formulate corresponding countermeasures in advance. For negotiators, it is beneficial to have the opportunity to stand on the other side's position and think about it. As victor Kim, a famous American entrepreneur, said, "any successful negotiation must start from the other side's point of view." This role-playing technology not only enables negotiators to understand each other, but also enables negotiators to understand themselves, because it gives negotiators an opportunity to objectively analyze themselves and notice some mistakes that are easily overlooked. For example, when negotiating with foreigners, they use too much local slang, lack of self-restraint facial expressions and ambiguous arguments.

At present, the teaching of Business Negotiation course in military colleges and universities is different from that of local colleges and universities in terms of the degree of openness. Most of the instructors still adopt the traditional teaching mode, which mainly focuses on theory teaching and interludes case teaching. The classroom teaching effect is predictable [4]. Even though some teachers intend to apply the simulation negotiation method to the course teaching of "business negotiation", there are still various problems in the application process, mainly in the following aspects:

\section{Student issues}

Subjectively, the enrollment of cadets mainly comes from low-level examinees, so most cadets have insufficient understanding of the cases assigned by the instructors and do not collect relevant materials seriously. In order to complete the negotiation task, they are too coping and praising, which results in the effect of the simulation negotiation method is affected to a certain extent. Objectively, the main way for students to acquire knowledge is classroom or book, and they lack practical experience. It is difficult to predict the possible problems in the negotiation cases before the simulation negotiation, and there will be many loopholes and deficiencies in the design of negotiation schemes. When the two sides have differences, it is difficult to find a breakthrough, and the atmosphere of the negotiation is relatively tense, even turning the simulated negotiation into a debate competition between the two sides [5].

\section{E. The issue of the instructor}

For the instructors' members who undertake the business negotiation course, the opportunities for participating in or observing the business negotiation activities of enterprises and institutions are very limited, and some even have no such opportunities. Therefore, most of the understanding and mastery of the simulation negotiation comes from second-hand information. The grasp of the simulation authenticity of the simulation negotiation is still insufficient. Therefore, the limitations of the practical experience of the instructors will inevitably affect the application effect of the simulated negotiation law in the course of business negotiation.

\section{F. Problems with teaching conditions}

The simulation negotiation method is applied to the classroom teaching of "business negotiation". Since it is classroom teaching, the activity space is limited to the classroom. Students can only use the desk as the negotiation table, and the seats of the main and auxiliary negotiators are not clear, so it is difficult to form the negotiation atmosphere of the formal negotiation room, and the implied communication between members of the negotiation team is not convenient. The negotiation time of each group is only about 45 90 minutes, and the limited time makes the negotiation unable to be fully carried out. Some groups cannot fully use various negotiation strategies within a limited time, and the two sides declare that the negotiation breaks down and fails to reach the expected negotiation effect.

\section{STUDY ON THE IMPLEMENTATION STEPS OF SiMULATION NEGOTIATION IN THE BUSINESS NEGOTIATION CLASS FOR CADETS}

\section{A. Classification of simulate negotiation}

There are two main ways to simulate negotiation.

1) Forming a negotiating team representing the opponent

If time permits, you can divide your negotiators into two groups, one as your own negotiator and one as the negotiator of the other party; it is also possible to draw some staff from relevant departments within the company to form another negotiating team. However, no matter which method is used, the two teams should constantly exchange roles. This is a formal simulation negotiation that allows for a comprehensive review of the negotiation plan and allows the negotiator to have prior knowledge of each link and issue.

\section{2) Letting a negotiating member play the opponent}

If time, cost and personnel are not allowed to arrange a more formal simulation negotiation, then the team leader should insist that a person act to play the other party and negotiate and interrogate the trading conditions of the company. Doing so also makes it possible for the head of the negotiating team to realize whether it is necessary to modify certain conditions or add some arguments, etc., and it will also enable the company personnel to recognize in advance the problems that may arise in the negotiations.

\section{B. Process of simulate negotiation}

The implementation process of the simulated negotiation law includes: selecting appropriate negotiation cases, grouping reasonably, simulating negotiation preparation stage, simulating negotiation process, and signing negotiation contracts.

\section{1) Selecting the right negotiation case}

Combine the characteristics of cadets, select appropriate cases, and combine the characteristics of cadets, try to choose the negotiation cases that are suitable for material procurement. For example common commodities in life (office supplies, 
computers, etc.), which is conducive for cadets to better grasp the conditions of commodity negotiation transactions. At the same time, it can also involve some social hotspot cases, so that cadets can collect and organize materials and let students discuss some real and typical cases in the classroom not only highlights the purpose of teaching, but is more easily accepted by the cadets.

\section{2) Grouping reasonably}

The number of instructors combined with the number of students is grouped according to the number of people, each group of 4-7 people is appropriate, the team leader is selected, the negotiating role is assigned, and the team members are united and strive to exert the overall advantage. The instructors fully understand the strengths and weaknesses of the students, and achieve complementary roles and balance in the group. At the same time, according to the wishes of the group, the specific content and details of the negotiations will be arranged to determine the negotiating opponents.

\section{3) Simulating negotiation preparation stage}

The trainees will conduct a comprehensive analysis of the case selected by the instructor and analyze the case to clarify their respective tasks. Collect information on the basis of small groups, making full use of electronic reading rooms and collecting materials. According to the content of the teaching, formulate the terms of negotiation and determine the negotiation objectives. Learn to use strategies and techniques to address specific issues that should arise in negotiations. At the same time, according to the division of interests of members, formulate a negotiation plan, complete the negotiation objectives, and finally guarantee the signing of the negotiation contract.

\section{4) Simulating negotiation process}

The negotiating parties participated in the simulation negotiations and were prepared to enter the negotiating room as required. Following the principles of business etiquette, they greet each other and elaborate on matters related to their respective negotiations, including opening, quotation, negotiation, and transaction. Terms and conditions relating to quality, packaging, quantity, insurance, transportation, claims, etc. The negotiation strategy and skills should be reflected in the process. Finally, the instructor and the group performance will summarize the negotiations. According to the results of the negotiations, analyze the degree of realization of the negotiating objectives of each group and make scientific suggestions.

\section{5) Signing negotiation contracts}

After the negotiations, the teams wrote a negotiation report to record the negotiation process and understanding. And hand in relevant business negotiation plans, simulated negotiation records, and finally signed a negotiation contract. The instructor combines the above-written materials in the semester assessment as part of the semester assessment.

\section{Perfect the Teaching Strategy of Simulation NEGOTIATION FOR CADETS}

In order to comprehensively cultivate the negotiating ability of cadets and improve the teaching effect of the simulated teaching method, there are still room for improvement and improvement in the above-mentioned problems in the simulation negotiation.

\section{A. Proper guidance and preparation in advance}

Before starting classroom teaching, students should be guided to prepare adequately before the simulation negotiation. The instructors should simulate the case materials or related business arrangements required for negotiation in advance to guide the students to prepare and supplement relevant knowledge according to the requirements of the negotiations. Allow participants to independently learn to collect all kinds of possible information in the negotiations, thus improving the effectiveness of the simulation negotiations.

\section{B. Creating a suitable environment and improve the hands-on ability of the students}

In the process of course teaching, the simulation practice base of professional teaching can be rationally utilized or modified. The laboratory platform is used to provide a simulated training environment for the students. The content can include negotiating table and chair design, negotiating material preparation, negotiating scene layout, etc., and placing sample information according to the actual situation of the negotiation to improve the practical ability of the students.

\section{Taking a variety of ways to improve the ability of the instructors}

In the process of curriculum construction, the instructors need to continuously improve their actual combat capabilities. In order to enhance their educational and teaching ability, the instructors can actively participate in the negotiation and practice activities of the colleges and universities, and enrich their negotiation experience and improve their practical teaching ability through visits. In the actual teaching process, simulation negotiation can be organized and implemented more flexibly.

\section{Supervise the trainees to correct their attitudes and ensure the teaching effect}

In order to ensure the effectiveness of the course teaching, it is necessary to correct the students' attitudes towards the practice of simulated negotiation in the teaching process. The simulation negotiation is carried out in the form of a group. To successfully complete the negotiation task, no cooperation between members is impossible. Through cooperation and mutual observation, members can deepen mutual understanding, learn to deal with different opinions, and obviously promote the unity of the teamwork spirit and the formation of good interpersonal communication skills among the students.

\section{SUMMARY}

Business negotiation is both a science and an art. The course of business negotiation itself is also a combination of theory and practice. Simulation negotiation teaching can achieve good teaching effect, but in order to maximize the application ability of cadets to the knowledge of related 
subjects, it is still necessary to continuously explore and practice the all-round cultivation of the creative and practical abilities of military cadets.

\section{REFERENCES}

[1] Zhao Qingsong. Application of Simulation Negotiation Method in the Teaching of International Business Negotiation[J]. Foreign Economic Relations and Trade, 2013(5): 147-149.
[2] Wu Qiong. Application of Simulation Negotiation Method in Teaching Reform of Business Negotiation[J]. Market Weekly, 2010.(3): 26-28.

[3] Lu Xiaohui. Exploration of Simulation Negotiation Practice in the Teaching of Business Negotiation[J]. Henan Business College Newspaper, 2008(6): 12-14.

[4] Cai Yonghong. Practice of Simulation Negotiation Teaching Method in Business Negotiation Course[J]. Education Science, 2010(5): 33-35.

[5] Li Kunyi, Wang Jun. Business Negotiation Skills [M]. Beijing: University of International Business and Economics Press, 2011. 